\title{
Obesity-Independent Inverse Association between Regular Alcohol Consumption and Hemoglobin $\mathrm{A}_{1 \mathrm{C}}$
}

\author{
Ichiro Wakabayashi \\ Department of Environmental and Preventive Medicine, Hyogo College of Medicine, \\ Nishinomiya, Hyogo, Japan
}

\section{Key Words}

Ageing · Alcohol $\cdot$ Diabetes mellitus · Glycated hemoglobin • Obesity

\begin{abstract}
Objective: The aim of this study was to determine whether obesity influences relationships between habitual alcohol drinking and hemoglobin $\mathrm{A}_{1 \mathrm{C}}\left(\mathrm{HbA}_{1 \mathrm{C}}\right)$ level. Methods: Japanese men (35-70 years old, $\mathrm{n}=24858$ ) were divided into non-, light ( $<22 \mathrm{~g}$ ethanol/day), moderate ( $\geq 22$ and $<44 \mathrm{~g}$ ethanol/day), and heavy ( $\geq 44 \mathrm{~g}$ ethanol/day) drinkers. Relationships of alcohol with $\mathrm{HbA}_{1 \mathrm{C}}$ were investigated in overall subjects and subjects of quartile groups for degree of obesity. Results: $\mathrm{HbA}_{1 \mathrm{C}}$ tended to be higher as quartiles of $\mathrm{BMI}$ and waist-to-height ratio increased. $\mathrm{HbA}_{1 \mathrm{C}}$ was significantly lower in light, moderate and heavy drinkers than in nondrinkers. These associations in overall subjects were also found in all of the quartiles of BMI and waist-to-height ratio, except for light drinkers in the 3rd and 4th quartiles of BMI and the 4 th quartile of waist-to-height ratio. Odds ratios versus nondrinkers for high $\mathrm{HbA}_{1 \mathrm{C}}$ were significantly lower than a reference level of 1.0 in all drinker groups, and these associations were not altered after adjustment for age, history of smoking, and BMI or waist-to-height ratio. Conclusion: The results suggest that alcohol consumption is associated with lower $\mathrm{HbA}_{1 \mathrm{C}}$ level independent of degree of obesity.

Copyright (C) 2012 S. Karger GmbH, Freiburg
\end{abstract}

\section{Introduction}

Habitual alcohol drinking is known to cause diverse effects on risk for atherosclerotic vascular disease. Heavy drinking increases the risk for stroke, especially hemorrhagic type of stroke such as cerebral hemorrhage and subarachinoid hemorrhage [1]. This harmful effect of alcohol is explained mainly by its blood pressure-elevating action [2]. On the other 
hand, light-to-moderate alcohol consumption is known to reduce the risk for ischemic heart disease [3], and this beneficial effect of alcohol is explained mainly by increase in HDL cholesterol [4] and decrease in blood coagulation activity [5, 6].

Diabetes mellitus is a major risk factor for atherosclerosis, and atherosclerotic vascular complications are major determinants for prognosis of patients with diabetes [7-9]. Although there is still debate, recent systemic reviews of previous prospective studies have shown that moderate alcohol consumption is associated with a decreased incidence of diabetes $[10,11]$. Coinciding with this, previous cross-sectional studies have shown that glycated hemoglobin, a marker reflecting long-term blood glucose level, was lower in moderate drinkers than in nondrinkers $[12,13]$. In most of those studies, Western populations were used as subjects. On the other hand, in Japanese, the risk for diabetes has been reported to be higher in moderate-to-heavy drinkers than in nondrinkers, and this association has been shown to depend on BMI: alcohol was a risk factor for diabetes in a low BMI population, while alcohol consumption was associated with reduced risk for diabetes in a middle-to-high BMI population [14-16]. Thus, there is a possibility that the relationship between alcohol drinking and the risk of diabetes is confounded by obesity. However, it is unknown whether the relationship between alcohol consumption and glycated hemoglobin differs in persons with and without obesity. The aim of this concise study was therefore to determine whether and how alcohol influences hemoglobin $A_{1 C}$ levels in a large population of Japanese men with different degrees of obesity evaluated by BMI, a general indicator of obesity, or waist-to-height ratio, an indicator of visceral obesity [17].

\section{Participants and Methods}

\section{Subjects}

The subjects were male workers aged $35-70$ years $(n=24,858)$ who had received periodic health checkup examinations at workplaces in Yamagata Prefecture in Japan. Men who had been receiving drug therapy for diabetes mellitus (3.8\%) were excluded from the subjects of this study. All of the subjects were of Japanese origin. A cross-sectional study was performed using a local population-based database for the above subjects. This study was approved by the Ethics Committee of Yamagata University School of Medicine. Histories of alcohol consumption, cigarette smoking, and illness were also surveyed by questionnaires.

\section{Evaluation of Alcohol Consumption}

Average alcohol consumption of each subject per week was reported on questionnaires during health examinations at each workplace. Since it is difficult to know the correct average alcohol consumption of occasional drinkers, only regular drinkers who drank almost every day were used as drinkers for analysis in this study. Usual weekly alcohol consumption was recorded in terms of the equivalent number of 'go', a traditional Japanese unit of a mount of sake (rice wine). The amounts of other alcoholic beverages, including beer, wine, whisky and shochu (traditional Japanese distilled spirit), were converted and expressed as units of 'go'. One 'go' approximately corresponds to $180 \mathrm{ml}$ of sake, $500 \mathrm{ml}$ of beer, $240 \mathrm{ml}$ of wine, $60 \mathrm{ml}$ of whisky, and $80 \mathrm{ml}$ of shochu. One 'go' contains about $22 \mathrm{~g}$ of ethanol, and this amount was used to separate moderate drinkers from light drinkers since it is generally accepted that alcohol intake should be reduced to less than $30 \mathrm{ml}$ or 20-30 g per day from the viewpoint of prevention of hypertension [18, 19]. Average daily alcohol intake (grams of ethanol per day) was then calculated. The subjects were divided into four groups according to ethanol consumption per day (nondrinkers; light drinkers $<22 \mathrm{~g}$ of ethanol per day; moderate drinkers $\geq 22$ g and $<44$ g of ethanol per day; heavy drinkers $\geq 44$ g of ethanol per day).

\section{Measurements}

Height and body weight were measured with light clothes at the health checkup. BMI was calculated as weight in kilograms divided by the square of height in meters. Waist circumference was measured at the navel level according to the recommendation of the definition of the Japanese Committee for the Diag- 
Table 1. Profile of subjects and comparison of each variable among the four alcohol groups

\begin{tabular}{llllll}
\hline \multirow{2}{*}{ Overall } & \multicolumn{2}{l}{ Drinkers } & & \\
\cline { 3 - 6 } & & & & & \\
& & Non & Light & Moderate & Heavy \\
\hline Number & $24,858(100 \%)$ & $7,341(29.5 \%)$ & $2,957(11.9 \%)$ & $9,022(36.3 \%)$ & $5,538(22.3 \%)$ \\
Age, years & $50.1 \pm 8.7$ & $49.0 \pm 9.1$ & $50.1 \pm 8.9^{* *}$ & $50.7 \pm 8.5^{* *}$ & $50.6 \pm 8.1^{* *}$ \\
Smokers, \% & 58.3 & 53.4 & 55.4 & $59.7^{* *}$ & $64.3^{* *}$ \\
Height, cm & $168.6 \pm 6.4$ & $168.4 \pm 6.7$ & $168.5 \pm 6.4$ & $168.6 \pm 6.2$ & $169.0 \pm 6.2^{* *}$ \\
Body weight, kg & $66.8 \pm 10.6$ & $67.7 \pm 11.9$ & $66.1 \pm 9.6^{* *}$ & $66.3 \pm 10.0^{* *}$ & $66.9 \pm 10.1^{* *}$ \\
BMI, kg/m ${ }^{2}$ & $23.46 \pm 3.23$ & $23.82 \pm 3.68$ & $23.25 \pm 2.92^{* *}$ & $23.28 \pm 3.03^{* *}$ & $23.37 \pm 3.02^{* *}$ \\
Waist circumference, cm & $83.4 \pm 8.6$ & $83.5 \pm 9.7$ & $82.7 \pm 8.0^{* *}$ & $83.2 \pm 8.1$ & $83.8 \pm 8.2$ \\
Waist-to-height ratio & $0.495 \pm 0.051$ & $0.496 \pm 0.058$ & $0.491 \pm 0.048^{* *}$ & $0.494 \pm 0.048^{*}$ & $0.496 \pm 0.048$ \\
Hemoglobin A1c, \% & $5.08 \pm 0.62$ & $5.15 \pm 0.69$ & $5.06 \pm 0.61^{* *}$ & $5.04 \pm 0.56^{* *}$ & $5.03 \pm 0.63^{* *}$
\end{tabular}

Numbers of subjects, means of each variable with standard deviations and percentages of smokers and drinkers are shown. Asterisks denote significant differences compared with nondrinkers $\left({ }^{*} \mathrm{p}<0.05\right.$; $* * \mathrm{p}<0.01)$.

nostic Criteria of Metabolic Syndrome [20]. Waist-to-height ratio was used as a marker of visceral obesity [17]. Fasted blood was sampled from each subject, and hemoglobin $A_{1 C}$ was determined by the latex cohesion method using a commercial kit (Determiner $\mathrm{HbA}_{1 \mathrm{C}}$, Kyowa Medex, Tokyo, Japan); coefficient of variation for reproducibility of the measurement was $\leq 5 \%$. Abnormally high hemoglobin $\mathrm{A}_{1 \mathrm{C}}$ was defined as being higher than $5.8 \%$.

\section{Statistical Analysis}

Statistical analyses were performed using a computer software program (SPSS version $16.0 \mathrm{~J}$ for Windows, Chicago, IL, USA). Mean levels of each variable were compared among the alcohol groups using analysis of variance (ANOVA) followed by Scheffé's F-test. In multivariate analysis, the mean levels, calculated after adjustment for variables such as age, history of smoking and body weight, BMI or waist-to-height ratio, were compared between the groups using analysis of covariance (ANCOVA) and then Student's t-test after Bonferroni correction. The percentage of smokers and the percentage of subjects showing high hemoglobin $\mathrm{A}_{1 \mathrm{C}}$ were compared between each drinker group and the nondrinker group using the chi-square test for independence. In logistic regression analysis, odds ratios of each drinker group versus the nondrinker group for high hemoglobin $\mathrm{A}_{1 \mathrm{C}}$ were calculated before and after adjustment for age, history of smoking and body weight, BMI or waist-to-height ratio. Probability (p) values less than 0.05 were defined as significant.

\section{Results}

\section{Comparison of Variables among the Alcohol Groups}

Each variable was compared among the four alcohol groups (table 1). Ages of light, moderate and heavy drinkers were significantly higher than the age of nondrinkers. Percentage of smokers was significantly higher in moderate and heavy drinkers than in nondrinkers. Height was significantly larger in heavy drinkers than in nondrinkers. Body weight and BMI were significantly lower in light, moderate and heavy drinkers than in nondrinkers. Waist circumference was significantly smaller in light drinkers than in nondrinkers. Waist-to-height ratio was significantly lower in light and moderate drinkers than in nondrinkers. Hemoglobin $\mathrm{A}_{1 \mathrm{C}}$ was significantly lower in light, moderate and heavy drinkers than in nondrinkers. 


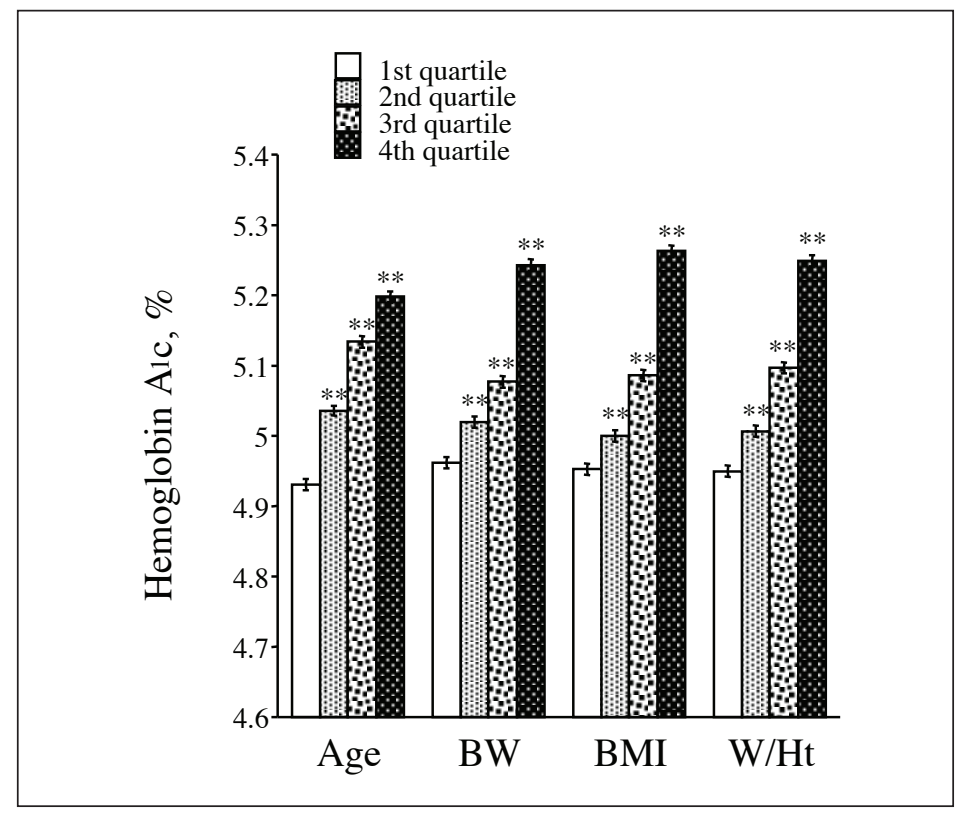

Fig. 1. Relationships of age, body weight (BW), BMI and waist-to-height ratio (W/Ht) with hemoglobin $A_{1 C}$. The values of age, body weight, BMI or waist-to-height ratio were arranged in ascending order, and then the subjects were divided into four groups of approximately equal sizes. Mean hemoglobin $\mathrm{A}_{1 \mathrm{C}}$ levels after adjustment for other variables were compared among the four quartile groups of each variable. The adjusted variables were history of smoking and BMI for quartiles of age, and age and history of smoking for quartiles of body weight, BMI and waist-to-height ratio. Mean values with standard errors are shown. Asterisks denote significant differences from the 1st quartile $(\mathrm{p}<0.01)$.

Relationships of Age and Obesity-Related Indexes with Hemoglobin $A_{1 C}$

Hemoglobin $\mathrm{A}_{1 \mathrm{C}}$ was significantly higher in the 2nd, 3rd and 4th quartiles of age, body weight, BMI, and waist-to-height ratio than in the 1st quartile of them (fig. 1). There were tendencies for hemoglobin $\mathrm{A}_{1 \mathrm{C}}$ to be higher as the quartiles of age, body weight, $\mathrm{BMI}$, and waist-to-height ratio increased.

Relationships between Alcohol Intake and Hemoglobin $A_{1 C}$ in the Quartiles of Age, Body

Weight, BMI and Waist-to-Height Ratio

Hemoglobin $A_{1 C}$ was compared among the four alcohol groups of each quartile of age (fig. 2A), body weight (fig. 2B), BMI (fig. 3A) and waist-to-height ratio (fig. 3B). In all quartile groups of age, body weight, $\mathrm{BMI}$ and waist-to-height ratio, hemoglobin $\mathrm{A}_{1 \mathrm{C}}$ was significantly lower in light, moderate and heavy drinkers than in nondrinkers, except for light drinkers in the 4th quartiles of all variables and in the 3rd quartiles of body weight and BMI.

Prevalence of High Hemoglobin $A_{1 C}$ in Each Drinker Group and Odds Ratio of Each Drinker Group versus the Nondrinker Group for High Hemoglobin $A_{1 C}$

Prevalence of high hemoglobin $A_{1 C}$ was significantly lower in light, moderate and heavy drinkers than in nondrinkers (table 2). Odds ratios versus nondrinkers for high hemoglobin $\mathrm{A}_{1 \mathrm{C}}$ were significantly lower than a reference level of 1.0 in light, moderate and heavy drinkers before and after adjustment for body weight, BMI or waist-to-height ratio in addition to age and history of smoking (table 2). There were no dose-dependent associations of alcohol intake with prevalence of high hemoglobin $A_{1 C}$ and with odds ratio versus nondrinkers for high hemoglobin $\mathrm{A}_{1 \mathrm{C}}$ (table 2). 


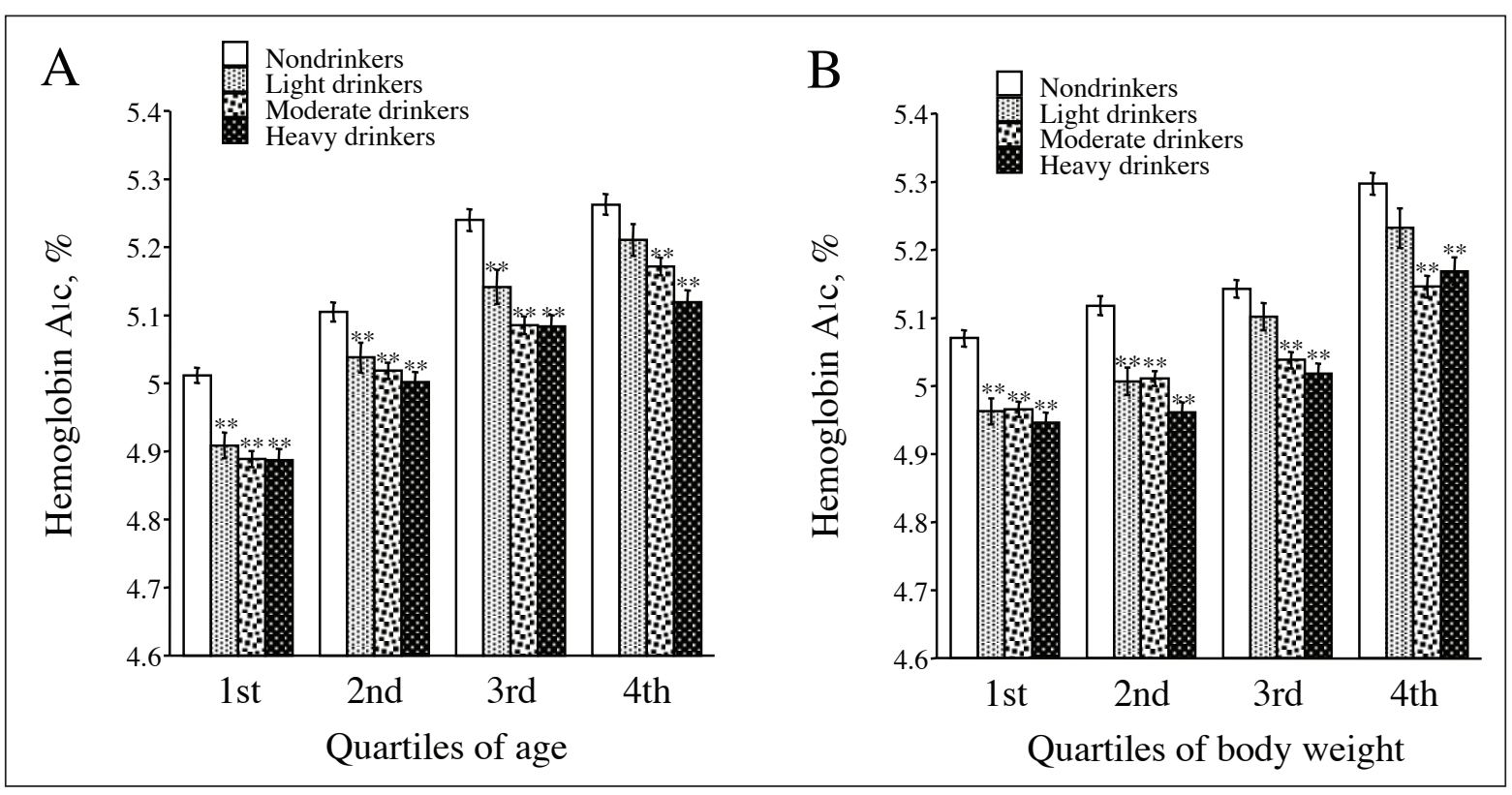

Fig. 2. Relationships between alcohol intake and hemoglobin $A_{1 C}$ in each quartile group of $\mathbf{A}$ age and $\mathbf{B}$ body weight. The values of age or body weight were arranged in ascending order, and then the subjects were divided into four groups of approximately equal sizes. Mean hemoglobin $\mathrm{A}_{1 \mathrm{C}}$ levels after adjustment for other variables were compared among the four alcohol groups in each quartile of age and body weight. The adjusted variables were age, history of smoking and BMI for quartiles of age, and age, history of smoking and body weight for quartiles of body weight. Mean values with standard errors are shown. Asterisks denote significant differences from nondrinkers $(p<0.01)$.

Table 2. Prevalence of high hemoglobin $A_{1 C}$ and odds ratio of each drinker group versus the nondrinker 1 Cgroup for high hemoglobin $\mathrm{A}_{1 \mathrm{C}}$

\begin{tabular}{lllll}
\hline & \multicolumn{2}{l}{ Drinkers } & & \\
\cline { 2 - 5 } & non & $\begin{array}{l}\text { light } \\
(<22 \mathrm{~g} / \text { day })\end{array}$ & $\begin{array}{l}\text { moderate } \\
(\geq 22 \text { and }<44 \mathrm{~g} / \text { day })\end{array}$ & $\begin{array}{l}\text { heavy } \\
(\geq 44 \mathrm{~g} / \text { day })\end{array}$ \\
\hline $\begin{array}{l}\text { Prevalence, \% } \\
\begin{array}{c}\text { Odds ratio } \\
\text { Crude }\end{array}\end{array}$ & 5.7 & $4.0^{* *}$ & $4.0^{* *}$ & $4.4^{* *}$ \\
$\begin{array}{l}\text { Adjusted } \\
\text { Adjusted }\end{array}$ & 1 & $0.68^{* *}(0.55-0.84)$ & $0.69^{* *}(0.60-0.79)$ & $0.76^{* *}(0.64-0.89)$ \\
Adjusted $^{3}$ & 1 & $0.73^{* *}(0.59-0.91)$ & $0.68^{* *}(0.59-0.79)$ & $0.74^{* *}(0.63-0.88)$ \\
$0.78^{*}(0.63-0.96)$ & $0.72^{* *}(0.62-0.84)$ & $0.81^{*}(0.68-0.96)$ \\
$0.75^{* *}(0.60-0.92)$ & $0.69^{* *}(0.60-0.80)$ & $0.76^{* *}(0.64-0.89)$ \\
\hline
\end{tabular}

Odds ratios with their 95\% confidence intervals in parentheses are shown. In addition to age and his-

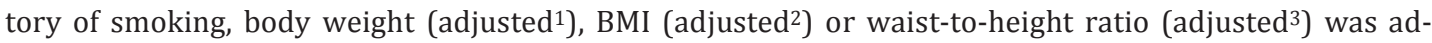
justed for calculation of odds ratios for high hemoglobin A1c. Asterisks denote significantly different prevalence compared with nondrinkers or significant odds ratios of each drinker group versus the nondrinker group $\left({ }^{*} \mathrm{p}<0.05 ;{ }^{* *} \mathrm{p}<0.01\right)$. 


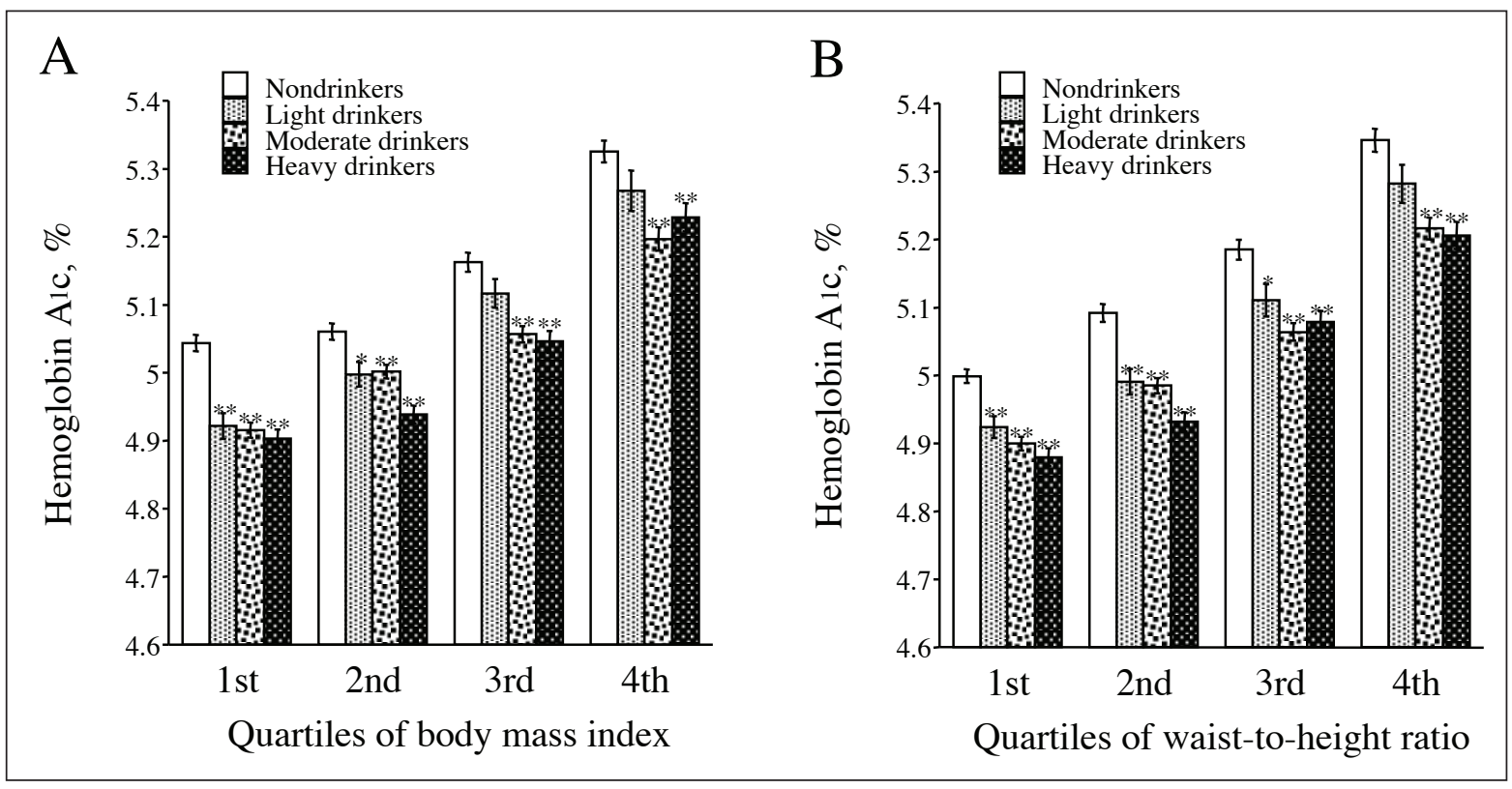

Fig. 3. Relationships between alcohol intake and hemoglobin $A_{1 C}$ in each quartile group of $\mathbf{A} B M I$ and $\mathbf{B}$ waist-to-height ratio. The values of BMI or waist-to-height ratio were arranged in ascending order, and then the subjects were divided into four groups of approximately equal sizes. Mean hemoglobin $\mathrm{A}_{1 \mathrm{C}}$ levels after adjustment for other variables were compared among the four alcohol groups in each quartile of variables. The adjusted variables were age, history of smoking and BMI for quartiles of BMI, and age, history of smoking and waist-to-height ratio for quartiles of waist-to-height ratio. Mean values with standard errors are shown. Asterisks denote significant differences from nondrinkers $\left({ }^{*}, p<0.05 ;{ }^{*}, p<0.01\right)$.

\section{Discussion}

This study demonstrated that the hemoglobin $A_{1 C}$ level became lower as the alcohol intake increased and that the prevalence of high hemoglobin $\mathrm{A}_{1 \mathrm{C}}$ was lower in drinkers than in nondrinkers. Although mean age was higher and BMI lower (both significantly) in drinkers than in nondrinkers, the association of alcohol intake with lower hemoglobin $\mathrm{A}_{1 \mathrm{C}}$ was not affected by controlling age and degree of obesity evaluated by BMI or waist-to-height ratio. Therefore, alcohol consumption is inversely associated with hemoglobin $\mathrm{A}_{1 \mathrm{C}}$ independently of age and degree of obesity. This study is the first study demonstrating obesity-independent association of alcohol with lower hemoglobin $A_{1 C}$ level. This finding is inconsistent with those of previous studies using Japanese subjects, in which increased risk of diabetes by alcohol drinking has been shown in slimmer men [14-16]. The reason for this discrepancy is unknown, but a possible explanation is a difference in frequency of drinking. In the present study, as mentioned in 'Participants and Methods', subjects in the drinker groups were regular drinkers who drank almost every day; opportunistic drinkers were excluded from the subjects. Interestingly, a previous study showed that frequency of alcohol consumption was inversely associated with incidence of diabetes and that the risk of diabetes compared with that in infrequent drinkers was reduced by $7 \%$ for each additional day per week when alcohol was consumed [21]. Moreover, frequency of alcohol consumption has been shown in a cross-sectional study to be inversely related to fasting $C$ peptide and insulin concentrations [22]. Therefore, frequent alcohol drinking is expected to be associated with lower hemoglobin $\mathrm{A}_{1 \mathrm{C}}$. Regarding age, an inverse relationship between moderate alcohol con- 
sumption and incidence of diabetes has been found both in subjects less than 60 years of age and in those 60 years or older [23]. Coincidently, the inverse association between alcohol intake and hemoglobin $\mathrm{A}_{1 \mathrm{C}}$ was not affected by age of subjects in the present study.

Body weight and BMI have been reported to modify the relationship between alcohol consumption and blood pressure: Alcohol consumption was more strongly associated with higher blood pressure in persons with lower body weight and BMI than in those with higher body weight and BMI [24]. On the other hand, the associations of alcohol consumption with higher HDL cholesterol and lower LDL cholesterol were not influenced by body weight [25]. The present study showed that the association between alcohol consumption and lower hemoglobin $\mathrm{A}_{1 \mathrm{C}}$ was not influenced by body weight and BMI. Thus, the influence of body weight and BMI on alcohol-risk factor relationships varies depending on the risk factor.

Alcohol is known to improve insulin sensitivity, and this action of alcohol is thought to be responsible for the lower incidence of type 2 diabetes in light-to-moderate drinkers in comparison to nondrinkers [26]. In fact, light-to-moderate drinking has been shown to lower fasting insulin levels and increase insulin sensitivity [27-29]. Therefore, improvement of insulin sensitivity by alcohol is considered as a reason for the inverse association between alcohol consumption and hemoglobin $\mathrm{A}_{1 \mathrm{C}}$.

There are some limitations of this study. This study was a cross-sectional study and could not reveal a causal relationship between alcohol and hemoglobin $A_{1 C}$, for which further prospective studies are needed. Hemoglobin $\mathrm{A}_{1 \mathrm{C}}$ reflects long-term blood glucose level and is influenced by dietary calorie intake and physical activity. However, no information on diet, nutrition, and habitual exercise was available in this study. The socioeconomic situation could also be a possible confounder for the alcohol-hemoglobin $\mathrm{A}_{1 \mathrm{C}}$ relationship but was not included in the database used in this study. In addition, detailed information on type of alcohol beverage was not available in this study, although the type of alcohol consumed has been reported not to be a significant factor for the association between alcohol and diabetes [21].

In conclusion, alcohol consumption is thought to be associated with lower hemoglobin $\mathrm{A}_{1 \mathrm{C}}$ level independently of age and degree of obesity. Regular alcohol drinking is thus suggested to reduce the risk of diabetes in both obese and non-obese people.

\section{Acknowledgements}

This work was supported by a Grant-in-Aid for Scientific Research from the Japan Society for the Promotion of Science (No. 21390211).

\section{Disclosure}

The author has no potential conflicts of interest to disclose.

\section{References}

1 Reynolds K, Lewis LB, Nolen JDL, Kinney GL, Sathya B, He J: Alcohol consumption and risk of stroke: a metaanalysis. JAMA 2003;289:579-588.

2 Klatsky AL: Alcohol and cardiovascular disease - more than one paradox to consider. Alcohol and hypertension: does it matter? Yes. J Cardiovasc Risk 2003;10:21-24.

- 3 Corrao G, Rubbiati L, Bagnardi V, Zambon A, Poikolainen K: Alcohol and coronary heart disease: a metaanalysis. Addiction 2000;95:1505-1523.

- 4 Ellison RC, Zhang Y, Qureshi MM, Knox S, Arnett DK, Province MA; investigators of the NHLBI Family Heart Study: Lifestyle determinants of high-density lipoprotein cholesterol: the National Heart, Lung, and Blood Institute Family Heart Study. Am Heart J 2004;147:529-535. 
Wakabayashi: Alcohol Consumption and Hemoglobin $\mathrm{A}_{1 \mathrm{C}}$

Krobot K, Hense HW, Cremer P, Eberle E, Keil U: Determinants of plasma fibrinogen: relation to body weight, waist-to-hip ratio, smoking, alcohol, age, and sex. Results from the second MONICA Augsburg survey, 19891990. Arterioscler Thromb 1992;12:780-788. Rubin R, Rand ML: Alcohol and platelet function. Alcohol Clin Exp Res 1994;18:105-110.

McCarron P, Greenwood R, Elwood P, Shlomo YB, Bayer A, Baker I, Frankel S, Ebrahim S, Murray L, Smith GD: The incidence and aetiology of stroke in the Caerphilly and Speedwell Collaborative Studies II: risk factors for ischaemic stroke. Public Health 2001;115:12-20.

- 8 Ho JE, Paultre F, Mosca L: Is diabetes mellitus a cardiovascular disease risk equivalent for fatal stroke in women? Data from the Women's Pooling Project. Stroke 2003;34:2812-2816.

- 9 Huxley R, Barzi F, Woodward M: Excess risk of fatal coronary heart disease associated with diabetes in men and women: meta-analysis of 37 prospective cohort studies. BMJ 2006;332:73-78.

10 Howard AA, Arnsten JH, Gourevitch MN: Effect of alcohol consumption on diabetes mellitus: a systematic review. Ann Intern Med 2004;140:211-219.

11 Baliunas DO, Taylor BJ, Irving H, Roerecke M, Patra J, Mohapatra S, Rehm J: Alcohol as a risk factor for type 2 diabetes: a systematic review and meta-analysis. Diabetes Care 2009;32:2123-2132.

$\$ 12$ Gulliford MC, Ukoumunne OC: Determinants of glycated haemoglobin in the general population: associations with diet, alcohol and cigarette smoking. Eur J Clin Nutr 2001;55:615-623.

13 Harding AH, Sargeant LA, Khaw KT, Welch A, Oakes S, Luben RN, Bingham S, Day NE, Wareham NJ: Crosssectional association between total level and type of alcohol consumption and glycosylated haemoglobin level: the EPIC-Norfolk Study. Eur J Clin Nutr 2002;56:882-890.

14 Tsumura K, Hayashi T, Suematsu C, Endo G, Fujii S, Okada K: Daily alcohol consumption and the risk of type 2 diabetes in Japanese men: the Osaka Health Survey. Diabetes Care 1999;22:1432-1437.

15 Watanabe M, Barzi F, Neal B, Ueshima H, Miyoshi Y, Okayama A, Choudhury SR: Alcohol consumption and the risk of diabetes by body mass index levels in a cohort of 5,636 Japanese. Diabetes Res Clin Pract 2002; 57:191-197.

-16 Waki K, Noda M, Sasaki S, Matsumura Y, Takahashi Y, Isogawa A, Ohashi Y, Kadowaki T, Tsugane S; the JPHC Study Group: Alcohol consumption and other risk factors for self-reported diabetes among middle-aged Japanese: a population-based prospective study in the JPHC study cohort I. Diabet Med 2005;22:323-331.

-17 Gruson E, Montaye M, Kee F, Wagner A, Bingham A, Ruidavets JB, Haas B, Evans A, Ferrières J, Ducimetière PP, Amouyel P, Dallongeville J: Anthropometric assessment of abdominal obesity and coronary heart disease risk in men: the PRIME study. Heart 2010;96:136-140.

-18 Chobanian AV, Bakris GL, Black HR, Cushman WC, Green LA, Izzo JL Jr, Jones DW, Materson BJ, Oparil S, Wright JT Jr, Roccella EJ; the National High Blood Pressure Education Program Coordinating Committee: The Seventh Report of the Joint National Committee on Prevention, Detection, Evaluation, and Treatment of High Blood Pressure: the JNC 7 report. JAMA 2003;289:2560-2572.

-19 European Society of Hypertension-European Society of Cardiology Guidelines Committee: 2003 European Society of Hypertension-European Society of Cardiology guidelines for the management of arterial hypertension. J Hypertens 2003;21:1011-1053.

20 Matsuzawa Y: Metabolic syndrome-definition and diagnostic criteria in Japan (in Japanese). J Jpn Soc Int Med 2005;94:794-809.

-21 Conigrave KM, Hu BF, Camargo CA Jr, Stampfer MJ, Willett WC, Rimm EB: A prospective study of drinking patterns in relation to risk of type 2 diabetes among men. Diabetes 2001;50:2390-2395.

-22 Meyer KA, Conigrave KM, Chu NF, Rifai N, Spiegelman D, Stampfer MJ, Rimm EB: Alcohol consumption patterns and $\mathrm{HbA}_{1 \mathrm{C}}$, C-peptide and insulin concentrations in men. J Am Coll Nutr 2003;22:185-194.

-23 Ajani UA, Hennekens CH, Spelsberg A, Manson JE: Alcohol consumption and risk of type 2 diabetes mellitus among US male physicians. Arch Intern Med. 2000;160:1025-1030.

24 Wakabayashi I: Impact of body weight on the relationship between alcohol intake and blood pressure. Alcohol Alcohol 2009;44:204-210.

25 Wakabayashi I: Influence of body weight on the relationships of alcohol drinking with blood pressure and serum lipids in women. Prev Med 2009;49:374-379.

-26 van de Wiel A: Diabetes mellitus and alcohol. Diabetes Metab Res Rev 2004;20:263-267.

-27 Mayer EJ, Newman B, Quesenberry CP Jr, Friedman GD, Selby JV: Alcohol consumption and insulin concentrations. Role of insulin in associations of alcohol intake with high-density lipoprotein cholesterol and triglycerides. Circulation 1993;88:2190-2197.

28 Kiechl S, Willeit J, Poewe W, Egger G, Oberhollenzer F, Muggeo M, Bonora E: Insulin sensitivity and regular alcohol consumption: large, prospective, cross sectional population study (Bruneck study) BMJ 1996;313: 1040-1044.

29 Konrat C, Mennen LI, Cacès E, Lepinay P, Rakotozafy F, Forhan A, Balkau B; D.E.S.I.R. Study Group: Alcohol intake and fasting insulin in French men and women. The D.E.S.I.R. Study. Diabetes Metab 2002;28:116123. 